\title{
How to manage ICTs mediated co-production: a public value perspective
}

\author{
Andrea Paletti \\ London School of Economics and Political Science \\ a.paletti@1se.ac.uk
}

\begin{abstract}
The adoption of ICTs mediated co-production to produce services is also becoming common in the public sector. The public sector literature discusses ICTs mediated co-production according to different organizational dimensions without considering that they mutually affect each other's. The analysis of ICTs mediated co-production according to single dimensions has leaded many public organizations to make poor strategic planning focusing just on specific aspects of their strategy. This paper provides a comprehensive framework that combines all the different perspectives simultaneously and help public managers to make better organizational strategies for public organizations. The framework is the result of the combination of the Strategic Triangle of Moore with the concept of assemblage and has been tested on the case of Transport for London (TfL). TfL is a public organization that manages public transportation and has developed an Open Data platform that enables more than 700 applications like City Mapper or Google Maps to co-produce the information service about public transportation.
\end{abstract}

\section{Introduction}

The failure of the New Public Management (NPM), the need of more personalized services and the availability of new ICTs that make easier the involvement of external actors in the production of public services, are making co-production more diffused among public organizations. The numerous Open Data initiatives are examples of co-production mediated by ICTs used by public organizations to increase transparency and enable third parties to develop public services such as the information service about public transportation [1]. Coproduction happens also through crowdsourcing that is used to involve external actors to accomplish specific tasks such as taking pictures of damaged streets to help local councils to map streets that need maintenance[2, 3].
ICTs mediated co-production has been widely debated in the public sector literature from different perspectives: the legal and policy making perspective [4-6] has discussed the regulations which are necessary to enable co-production; the organizational perspective $[3,7-10]$ has discussed the organizational changes necessary to implement co-production; the technical perspective [11-13] has described how technologies should be designed to enable coproduction; the performance oriented perspective [14] has discussed how to measure the effectiveness of co-produced services. All these perspectives correspond to the different organizational dimensions that affect the success of the production of a public service. Public managers should simultaneously consider all the four dimensions as deeply intertwined [15] when they plan a new organizational strategy to successfully manage co-production. The literature does not provide a comprehensive framework where all the different perspectives are included and reciprocally affect each other's. Therefore, the research question is how can a public sector organization plan its organizational strategy to manage ICTs mediated co-production?

The research builds on the strategic triangle of Moore [16-20] and on the concept of assemblage to provide a comprehensive framework that includes all the dimensions that public managers should consider when they are planning the organizational strategy of their organizations. The framework is then applied to explain the organizational strategy behind Transport for London (TfL) that uses an Open Data platform to co-produce the information service about public transportation in London. The main contribution of the paper is the creation of a comprehensive framework to plan the organizational strategy of a public organization.

The paper is structured as follows: the first part discusses the gap in the literature; the second part presents the theoretical framework; the third part explains the methodology used to test and validate the framework; the fourth part presents the case study; the fifth part applies the theoretical framework to the case of TfL. After a discussion of the results, 
the paper ends presenting the conclusion part where the main contributions and findings of the paper are summarized.

\section{The raise of ICTs mediated co- production}

The concept of co-production was originally developed by Ostrom (1972) in her study about the Chicago Police and defined as "the process through which inputs used to produce a good or service are contributed by individuals who are not in the same organization" (Ostrom, 1972: p.1073). In her study she showed that the active contribution of citizens to help police officers to monitor their neighbours used to make Chicago a safer city because the eyes of policemen were combined with the thousands of eyes of citizens ready to advise or call the police [21]. Coproduction based on the above concept has never identified its own specific literature. Many of the contributions that are meaningful for the purpose of this research can be found in the public management literature [2, 9, 22-27] that has recently restored this old concept. The growing interest in co-production is also at the base of emerging alternative approaches to public management such as New Public Governance (NPG) or Networked Governance that promotes inter-agency cooperation, partnerships and cooperation with external actors in the co-production of public services[28, 29].

However, in the recent years the number of coproducers is increasing in the private and also in the public sector thanks to the introduction of ICTs that facilitate the collaboration of several actors making the adoption of co-production easier than before [29, 30]. This growing form of production is related to a higher availability of computational resources and information among the population, low capital to create network associations and to the granular nature of information systems and processes that can be dissolved in subtasks and routines [30, 31]. All these factors have contributed to the creation of "distributed, modular, and flexible arrangements of collaboration by which the accomplishment of information-based products or services can be pursued" (Kallinikos, 2011: p.133).

An example of ICTs mediated co-production in the public sector is the U.S. Agency for International Development (USAID) in charge to manage cooperation and development projects worldwide. USAID has organized a special program called "Grand Challenges"1 which uses crowdsourcing to

\footnotetext{
${ }^{1}$ https://www.usaid.gov/grandchallenges
}

find solutions to its most difficult challenges in the field of economic and humanitarian assistance. Another example is the Environmental Protection Agency (EPA) of the USA that provides an "Air Sensor Toolbox for Citizen Scientists" to enable citizens to crowdsource data about air-pollution helping local authorities to identify the most polluted areas and the possible causes for such pollution [32]. An additional example is Peer-to-Patent ${ }^{2}$ the crowdsourcing program of the US Patent and Trademarks Office (USPTO) to involve more than 2,500 volunteers from 152 countries to help the office in the process of reviewing patents [33]. Similarly in 2001 NASA created a "micro-tasking platform" to coordinate 85.000 volunteers to analyse through smartphones a vast amounts of satellite imageries of Mars[34, 35].

We have studies that provide valuable explanations of how to manage ICTs mediated coproduction from different perspectives. From a policy making and legal point of view, ICTs mediated co-production needs specific regulations and dedicated policies that can indicate to public organizations how external actors should be engaged $[36,37]$. In the Open Data case, governments had to classify from a regulatory perspective what data public organizations can open and which are the privacy restrictions [1, 4]. From a technical perspective, ICTs mediated co-production requires specific infrastructures and technologies that can sustain the involvement of several external actors [37, 38]. Open Data requires a dedicated infrastructure usually based on an APIs (Application Programming Interfaces) platform and a format of the data that enables third parties to access the data [13].From an organizational perspective, coproduction requires the adoption of new production processes that go beyond the boundaries of the organization [1, 37]. For example, specific procedures and support have to be designed in order to manage the ecosystem of applications and services that are based on Open Data[8]. From an evaluation perspective[36] the co-produced services need a different type of evaluation because the value delivered is co-produced with external actors. The Canadian municipal governments created new key performance indicators (KPIs) to measure the number of services co-produced with third parties and their economic impact[4, 14].

The gap in the literature consists in the lack of a comprehensive framework that combines all the different perspectives simultaneously. This gap in the literature has created negative implications among

\footnotetext{
${ }^{2}$ http://www.peertopatent.org/
} 
public managers that have developed their organizational strategies focusing mainly on a specific perspective without considering the other dimensions[8]. The lack of a comprehensive understanding of the organizational strategy has had negative impact on the success of co-production projects $[14,29]$.

Therefore, the research question is how can a public sector organization plan its organizational strategy to manage ICTs mediated co-production? The next part proposes the theoretical framework that can help to answer to this research question and fill the current gap in the literature.

\section{The theoretical framework}

The failure of the NPM in applying business approaches to plan strategies for public sector organizations, has leaded the public sector literature to research a new path. In this new path, the focus is not anymore on delivering value for the single client but on delivering public value. The public value concept, introduced by Moore (1995) "embodies the goals and aspirations citizens have for the society as a whole" (Alford 2002: p.339-340). The switch from private to public value has implications for the strategic planning of an organization because the service has to satisfy a collective need and not an individual need.

Moore (1995) has proposed a framework called the "Strategic Triangle" to help public managers to plan an organizational strategy for their organization and to produce a public service that could deliver public value[17, 20, 39]. The most recent researches about the "strategic triangle" have expanded its explanatory power without affecting its original structure that still indicates three main dimensions of the organizational strategy that a public manager should consider to ensure that the service produced really delivers public value[40-42].

The first dimension is named authorizing environment. Citizens through elections elect the parliament and local councils in order to represent their aspirations and needs. At this first stage, public managers interact with the political sphere to understand what public value should be delivered through a service [17, 43]. Politicians formally indicate and authorize the public value that should be delivered through policies and regulations that address and limit the action of public managers [4345].

Once individuated the service that should be delivered and once selected the most suitable way to produce the service, public managers pass to the second dimension of the organizational strategy that considers the operational capabilities necessary to materially produce the service. Public managers have to arrange the funds needed to finance the service, the number of staff, the skills and technologies necessary for the production of the service [20]. The resources and capabilities necessary to produce the service can be found within their own organization or outside[20, 44]. Public managers have also to define the roles and the tasks of each actor involved in the production of the service [20, 46, 47].

The third dimension is the evaluation of public value. After the production of the service, public managers should evaluate if the service has delivered public value. Public managers define together with politicians certain targets or KPIs to assess if the service has satisfied citizens or not.

The Strategic Triangle does not discuss ICTs mediated co-production and considers ICTs as neutral tools to increase the efficiency which do not have any impact on the other organizational elements and vice versa $[20,39,48]$. The strategic triangle then has to be combined with the concept of assemblage [15].

Assemblages are the result of the encounter of large ICTs systems and existing organizational structures (Lanzara, 2009: p. 11-12). Consequently, in the new framework (figure 1) the three organizational elements should be combined with technology as part of an assemblage. Assemblages are hybrid identities which include a plethora of human and not-human actors such as political authorities, managers, technical requirements, regulations, and standards $[15,49,50]$. Therefore, the concept of assemblage implies that each element and process necessary to produce the public service is intertwined as part of a unique body.

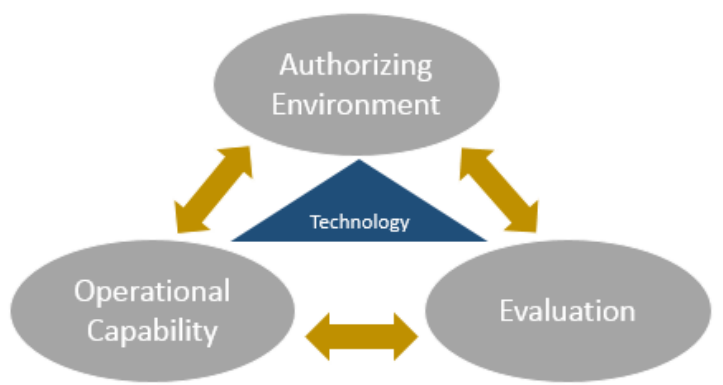

Figure 1. The Strategic Triangle of Public Value Creation complemented with the concept of assemblage

Then the changes of one element of an assemblage implies changes also of the other elements [15].

Assemblages can be closed or open. In a closed assemblage, all the elements and processes are totally 
inside the organization. Conversely in an open assemblage part of the organizational elements and processes are totally or partially external to the organization. Organizations can pass from a closed to an open assemblage and vice versa through a process of organizational transformation where different organizational elements are disassembly and reassembly according to a new configuration. This process is different in each organization because depends on the internal institutional settings, political context and on the logic of production that has been adopted. The process of reassembly requires time and efforts because it is necessary to transform and to restructure not only the existing ICT infrastructure but also cognitive frameworks as well as routines and production dynamics[51].

A reconfiguration of the organizational strategy can be necessary in case of changes in the authorizing environment, operational capabilities, technology or in the evaluation part. Changes in only one of these parts imply changes also in the other parts. If for example the parliament decides that hospitals cannot collaborate anymore with the Red Cross volunteers, then all hospitals have to change their internal regulations, reorganize the work of the medical personel and change how the medical service is evaluated. Similarly, the introduction of a new technology that enables the police to find criminals utilizing CCTV cameras and facial recognition, implies the need of new regulations about privacy, changes in how the police patrol public areas and also new ways to evaluate the effectiveness of the policing service. Another example can be if the national healthcare bureau starts evaluating hospitals according to new KPIs which focus more on the costs of medical treatments. Hospital managers will have to plan a new organizational strategy. Dedicated protocols and work practices will be introduced to reduce costs. Doctors will provide cheap or less medical treatments to citizens and ICTs would be deployed to decrease costs.

The theoretical framework presented in Figure 1 and explained in this paragraph is going to guide the data collection to verify if it can explain the organizational strategy of $\mathrm{TfL}$ and if it can be complemented with new findings.

\section{Methodology}

This section explains how data were collected and analyzed in order to answer to the research question. The research focuses on the current organizational strategy of TfL to manage ICTs mediated coproduction. The case study is the Digital Unit of TfL called Online at TfL. Online at TfL is one of the departments of TfL, counts more than 40 people and is in charge to manage all the digital services. This case represents a rare contemporary example of a public organization that has successfully adopted ICTs mediated co-production. Although the Open Data initiative started officially in 2010, the success and the change in how the information service is produced emerged to the public just in the last years thanks to the diffusion of apps like CityMapper, GoogleMaps or Moovit which are powered by the APIs of TfL. This investigation represents a first attempt to research a phenomenon that previously was not accessible and that helps to expand and complement the literature of ICTs mediated coproduction. As it is clear from the research question, the research is explanatory and aims at developing an explanation about how a public organization can plan its organizational strategy to manage ICTs mediated co-production[52].

The Open Data platform materially represents how TfL orchestrates its internal and external resources to co-produce the information service. The unit of analysis of this study is the assemblage [15] constituted by the coupling of the Open Data platform and all the processes, operations and production dynamics embedded in the organization of the Digital Unit. The Open Data platform ${ }^{3}$ represents what we can materially see of the assemblage that allows the ICTs mediated coproduction of the information service. The platform is composed of a back-end and a front-end. What we see today when we access to the developer's area is the result of the interplay of the organizational elements represented by the three dimensions and the back-end that is represented by the ICT infrastructure [53].

\subsection{Data Collection}

The data collection lasted six months, from January to July 2017. It is exclusively based on collection of documents and interviews. The researcher has accessed the field with a priori insight into how the organizational strategy can be explained (Figure 1). Nevertheless, due to the complexity and situated nature of the reality, the researcher has kept his understanding open to what emerges from documents and his meetings with informants [54]. Accordingly, the semi-exploratory data collection has been based on more than one hundred documents. The documents collected come from the TfL blog 4 , official reports, documentation and academic research about the TfL Open Data initiative. Five

\footnotetext{
${ }^{3}$ https://tfl.gov.uk/info-for/open-data-users/

${ }^{4}$ https://blog.tfl.gov.uk/
} 
interviews of 40 minutes each with $\mathrm{TfL}$ managers directly involved in the Open Data initiative and three additional interviews with managers of applications like Moovit and CityMapper were conducted to confirm the understanding of the case and the information coming from the documents.

\subsection{Data analysis}

The documents and the interviews collected have been analyzed through a hybrid approach of thematic analysis [55] that mixes deductive and inductive approaches. This means that some of the categories derived from the theoretical framework (figure 1) and others emerged from the field (Haas \& Kraft, 1984; Trochim, 1989).

The analysis has looked at common themes that represent the shared idea and understanding of different sources about the organizational strategy to co-produce the information service through the Open Data platform. Finally, the results of the analysis have been interpreted to confirm, complement or reject the theoretical framework (figure 1).

\section{The Case of Transport for London}

The case study specifically focuses on the information service about public transportation which is one of the ancillary public services that TfL provides to facilitate the journey experience of citizens and tourists across London. TfL used to deliver the information service only through SMS, emails, website, screens, maps and the personnel at the tube stations. Nevertheless, TfL struggled to provide a punctual and personalized information about public transportation especially during strikes that usually generate a high demand of information caused by the disruption of the transportation service. Therefore, TfL public managers, introduced an Open Data platform, changed the organizational strategy of TfL and started co-producing with external developers different options of information service such as applications like City Mapper or Google Maps. Thanks to the introduction of the Open Data platform, today the information service about public transportation is currently provided through TfL internal channels (TfL personnel, website, SMS service, screens, email, etc..) and through more than 700 smartphone applications that in 2012 were downloaded 4 million times $(3,979,300)$ [58].

The Open Data initiative was conceptualized in 2007 when Online at TfL started experimenting a new way to produce the information service allowing third parties to integrate TfL widgets on web content aggregators such as iGoogle [59]. Although the first experiments were successful, the opening of data about public transportation and a major involvement of the developer community did not fully convince the board and the other TfL managers.

Only in 2008 the political context started to change, the discussion about Open Data reached the interest of the UK government that created a dedicated research group called the Power of Information Taskforce to advise the government about how public information could help citizens and government to improve services and transparency. Following the same perspective, the 2010 Conservative Party Manifesto and the policies of the Mayor of London Boris Johnson made evident the will to open data in order to make government and public organizations more transparent. From a policy point of view these initial political contributions considered Open Data in relation to transparency and not for the creation of public services. Nevertheless, this political thinking influenced a political change of the Greater London Authority (GLA) that in 2010 launched the London Datastore ${ }^{5}$ an API platform that collects data from all public organizations under the control of the GLA. Thanks to this clear change of the GLA policies, the TfL board was then persuaded to open its datasets and to officially launch the Open Data platform in 2012 [59].

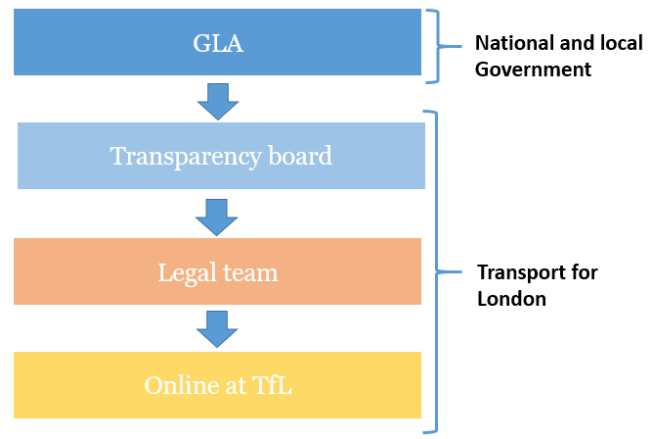

Figure 2. Decision making process to manage the Open Data platform

Together with the launch of the platform, a new decision making process was introduced (figure 2). The most influential TfL managers were invited to form a board called "transparency board". The transparency board is in charge to implement the GLA policy about Open Data and decide which datasets should be open and which not also considering the needs of the developer community.

As part of the decision making process the TfL legal team verifies possible security or privacy implications related to the opening of the datasets that the board has selected. The datasets are owned by different departments, therefore the department that owns the selected dataset has to start working

\footnotetext{
${ }^{5}$ https://data.london.gov.uk/
} 
with Online at TfL to publish the datasets on the Open Data platform. This decision making process is based on cooperation and constant interaction among the different stakeholders.

The introduction of the platform has required also changes of other organizational elements of TfL. First of all in 2010 TfL started adopting a cloud infrastructure in order to sustain the increasing demand of data from the applications developed by external parties. The demand of more efficient and accessible data induced TfL in 2015, to adopt a unified API.

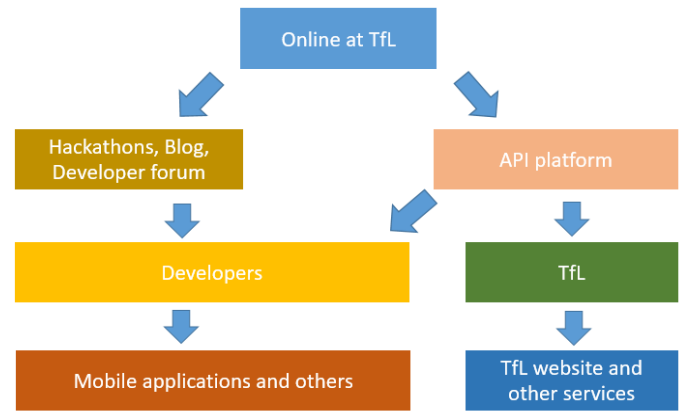

Figure 3. Production process to support the Open data platform

In addition, the Open Data platform that is technically an APIs platform, is used by external developers and by TfL developers that thanks to the cloud are technically enabled to adopt new work practices inspired by the Agile methodology, to experiment and prototype new features. These new work practices are part of a shared vision that has addressed the organization to be more responsive to citizens' needs. This change of mind-set in the work practices has leaded to the development of new services such as the "Journey Planner" on the TfL website or other additional features to personalize the information about public transportation. In addition, the collaboration with external developers, has been facilitated by some TfL managers and developers of Online at TfL that shared sympathy for the Open Source values and consider external developers not as competitors but as valuable assets for the development of better services. However, the perspective about the importance of openness was not shared in the other departments of TfL. Therefore, managers like Phil Young head of Online at TfL and Vernon Everitt Managing Director of Customers, Communication and Technology acted as a "digital champions" in the organization to promote the importance of Open Data and openness.

Beyond the changes in the human resources and in the competences of the organization, the adoption

\footnotetext{
${ }^{6} \mathrm{https}: / /$ tfl.gov.uk/plan-a-journey/
}

of the API platform and the Cloud infrastructure required more financial resources on the maintenance of the infrastructure than on the development of services. Changes involved also financial process for example the cost of cloud service could not be predicted and new financial plans had to be designed.

The adoption of the Open Data platform required also a new production process of the information service. Once Online at $\mathrm{TfL}$ receives the authorization to publish the dataset, if necessary the format of the data is converted in a more suitable format and then the API of the dataset is published on the platform. TfL managers explain through the TfL blog ${ }^{7}$ or the Tech Forum ${ }^{8}$ how to use the datasets and solve possible technical issues.

TfL organizes also events called "Hackathons" where developers can meet TfL managers and technicians for one day to develop prototypes of applications and clarify how to better use TfL's APIs. The constant and close relationship of external developers and TfL personnel has made the process of co-production of the information service very effective because TfL can respond well to the needs of developers and facilitate their work.

The 7800 registered developers and 700 apps produced by third parties are indicators used by TfL managers to measure the effectiveness of the production process. Moreover in $2012 \mathrm{TfL}$ saw a rise from $51 \%$ to $70 \%$ of citizens using its website and in the same year the number of citizens using third parties' services rise from $27 \%$ to $40 \%$.

\section{The Case Analysis}

The TfL organizational strategy for the co-production of the information service is the result of years of experimentation, adaptation and reconfiguration of different organizational elements and processes. Looking at the case through the lens of the theoretical framework (figure 1), is clear that the success of TfL Open Data initiative is related to a good organizational strategy that has aligned all the dimensions to provide a better personalized information service about public transportation.

TfL wanted to adopt Open Data to allow third parties to produce alternative options of information service and increase the chances to deliver public value. In $2007 \mathrm{TfL}$ started experimenting the technology to allow external developers to use TfL data for their applications, but only in 2010 a clear political mandate facilitated a progressive adoption of Open Data at TfL.

\footnotetext{
${ }^{7}$ https://blog.tfl.gov.uk/

${ }^{8} \mathrm{https}$ ://techforum.tfl.gov.uk/
} 


\begin{tabular}{|c|c|c|c|c|c|}
\hline \multicolumn{4}{|c|}{ Organizational Goal and Production plan } & \multicolumn{2}{|c|}{ Authorizing Environment } \\
\hline \multicolumn{2}{|c|}{$\begin{array}{l}\text { Service produced } \\
\text { TfL aims at producing a } \\
\text { personalized information } \\
\text { service about public } \\
\text { transportation }\end{array}$} & \multicolumn{2}{|c|}{$\begin{array}{l}\text { Mode of production } \\
\text { - In-House (TfL } \\
\text { website, SMS, Email) } \\
\text { - Open-sourced (Apps } \\
\text { developed by third } \\
\text { parties) }\end{array}$} & $\begin{array}{l}\text { Political } \\
\text { authorization } \\
\text { - } 2008 \text { Power of } \\
\text { Information Taskforce } \\
\text { - } 2010 \text { Conservative } \\
\text { Party Manifesto }\end{array}$ & $\begin{array}{l}\text { Legal authorization } \\
\text { - } 2010 \text { Open } \\
\text { Government Licence } \\
\text { - TfL licencing } \\
\text { agreement for Open } \\
\text { Data }\end{array}$ \\
\hline \multicolumn{5}{|c|}{ Operational Capabilities } & Evaluation \\
\hline $\begin{array}{l}\text { Skills } \\
\text { - Agile } \\
\text { - Innovation }\end{array}$ & $\begin{array}{l}\text { Technold } \\
\text { - } 2010 \mathrm{C} \\
\text { infrastr } \\
\text { - } 2015 \mathrm{Ur} \\
\text { API }\end{array}$ & & $\begin{array}{l}\text { Human Resources } \\
\text { - Agile development } \\
\text { - Open Source } \\
\text { mindset } \\
\text { - Digital Champions }\end{array}$ & $\begin{array}{l}\text { Finance } \\
\text { - New cost structure } \\
\text { for cloud } \\
\text { - More investment } \\
\text { on the platform }\end{array}$ & $\begin{array}{l}\text { KPIs } \\
\text { - } \text { No complaints } \\
\text { - } 7800 \text { developers } \\
\text { - } 700 \text { Apps }\end{array}$ \\
\hline
\end{tabular}

Table 1. The Strategic Triangle of public value Creation complemented with the concept of assemblage

As agreed by Vernon Everitt and Phil Young "the clear policy of [the GLA] helped TfL to prioritize the release of data and achieve it faster than would otherwise have been the case" and as observed by Vernon Everitt "no-one needed to persuade our political masters at the GLA that this was a good idea because their default setting was already openness"

The changes of authorizing environment were followed by gradual changes of the operational capabilities of TfL in order to enable third parties to develop applications utilizing TfL Open Data.

Vernon Everitt describes the changes of the operational capabilities through these words: "between 2007 and 2010 we were feeling our way a bit. And then by 2011 we'd got the hang of it and seen that not only do you have to make the data freely and openly available, you had to do it in a form that people could consume straightforwardly. Hence the development of more sophisticated APIs so people could plug in and play. And then in 2012 our bus departure API was launched, and we did a whole bunch of stuff for the Olympics which gave it added impetus " 10 .

Nevertheless, the introduction of a new technology had to be coupled with changes in the work practices such as the adoption of Agile methodologies for the development of services. A new production process (figure 3 ) was also developed to sustain the co-production of the service.

The co-production of the information service through the platform has also required changes in the evaluation process. In an open assemblage is difficult to determine if public value is delivered or not. As mentioned by Phil Young is difficult to find specific

\footnotetext{
${ }^{9}$ Interview Pag 7 2016, B.Hogge

${ }^{10}$ Interview Pag 7 2016, B.Hogge
}

numbers that can describe the success of Open Data. Everitt thinks that an evident result is that the combination of TfL website and third parties apps "alleviated at least some of the aggravation" 11 caused by strikes and citizens stopped complaining[59].

Therefore, TfL managers adopted new KPIs to evaluate the overall satisfaction about the information service without considering if the service used is offered directly by TfL or co-produced with third parties.

\section{Results}

The main result of the research is the creation of a framework that can help public managers to plan the organizational strategy of their public organizations. The framework of table 1 has been built on the theoretical framework represented by figure 1 .

As shown by the case of TfL, the framework (table 1) should not be read as a step by step process to plan an organizational strategy. The organizational strategy is the result of gradual changes and can mutate overtime. A change in any part of the framework implies changes also in the other parts. For example, a change of policies and regulations would require adjustments of the production and also of the evaluation process. The availability of a new technology can induce a public manager to rethink the production process and ask to politicians dedicate laws or policies to allow the new production of the service. Therefore, public organizations need to constantly readapt their organizational strategy modifying their organizational elements but also their processes in order to be able to deliver the value that

\footnotetext{
${ }^{11}$ Interview pag 13 2016, B.Hogge
} 
citizens expect. Furthermore, the framework presented in table 1, graphically shows only the organizational elements of the organizational strategy but as shown in the case of TfL, public managers should re-think also how to redesign the organizational processes.

Another important point that emerges from the case, is that public managers should make a legal and political analysis and contextualize their decisions in a specific political context. TfL managers had to promote their idea both internally and externally to persuade politicians and managers about the opportunities offered by co-production.

It is also important to underline that the framework developed in this research can be used to plan the organizational strategy of both closed and open assemblages $[15,53,60]$.

\section{Conclusions}

ICTs mediated co-production is becoming a widespread practice in the private and public sector. The literature has studied ICTs mediated coproduction from different perspectives making difficult for public managers to understand which organizational dimensions they should consider when they plan a new organizational strategy. The literature does not currently provide a framework that includes all the main perspectives to plan an organizational strategy to manage ICTs mediated coproduction.

This research fills this gap providing a comprehensive framework that builds on the Strategic Triangle that is usually used to plan the organizational strategies of public sector organizations but that does not consider ICTs mediated co-production[20,61]. Therefore, this paper has combined the Strategic Triangle of Moore with the concept of assemblage [15] to better explain how different organizational dimensions and technology mutually affect each other's. The framework has been then tested on the case study of TfL.

The paper makes two contributions. The first contribution is a framework (table 1) that shows all the organizational dimensions that public managers should consider and carefully aligned when they plan the organizational strategy of their organizations. The second contribution is the extension of the Strategic Triangle of Moore (figure 1) that represents a theoretical bridge between the public value and egovernment literature.

It is important to highlight that this study has limitations. In this paper, we do not mention the importance of governance of a public organization that affects how the organizational goals and the modes of production are selected. Governance decides the public value impact of a service and this might affect the organizational strategy of a public organization [61].

\section{References}

1. Toots M, McBride K, Kalvet T, Krimmer R (2017) Open Data as Enabler of Public Service Co-creation: Exploring the Drivers and Barriers. Proc 2017 Int Conf E-Democracy Open Gov (CeDEM 2017) (xx-xx) Krems, Austria IEEE Comput Soc [forthcoming]. doi:

\subsection{9/CeDEM.2017.12}

2. Davison RM, Wagner C, Ma LCK (2005) From government to e-government: a transition model. Inf Technol People 18:280-299. doi: $10.1108 / 09593840510615888$

3. Cordella A, Paletti A (2017) Value creation, ICT, and co-production in public sector. In: Proc. 18th Annu. Int. Conf. Digit. Gov. Res. - dg.o '17. ACM Press, New York, New York, USA, pp 185-194

4. Zuiderwijk A, Janssen M (2014) Open data policies, their implementation and impact: A framework for comparison. Gov Inf Q 31:17-29. doi: 10.1016/j.giq.2013.04.003

5. Anuradha J, Moore M (2004) Institutionalised Coproduction: Unorthodox Public Service Delivery in Challenging Environments. J Dev Stud 40:3149. doi: 10.1080/00220380410001673184

6. Howlett M, Kekez A, Poocharoen O (2017) Understanding Co-Production as a Policy Tool: Integrating New Public Governance and Comparative Policy Theory. J Comp Policy Anal Res Pract 1-15. doi: 10.1080/13876988.2017.1287445

7. Brandsen T, Pestoff V (2006) Co-production, the third sector and the delivery of public services. Public Manag Rev 8:493-501. doi: 10.1080/14719030601022874

8. Brown A, Fishenden J, Thompson M, Venters W (2017) Appraising the impact and role of platform models and Government as a Platform (GaaP) in UK Government public service reform: Towards a Platform Assessment Framework (PAF). Gov Inf Q 34:167-182. doi: 10.1016/j.giq.2017.03.003

9. Gascó M (2017) Living labs: Implementing open innovation in the public sector. Gov Inf Q 34:9098. doi: 10.1016/j.giq.2016.09.003

10. Gil-Garcia JR, Helbig N, Ojo A (2014) Being smart: Emerging technologies and innovation in the public sector. Gov Inf Q 31:I1-I8. doi: 10.1016/j.giq.2014.09.001

11. Fishenden J, Thompson M (2013) Digital government, open architecture, and innovation: Why public sector it will never be the same again. J Public Adm Res Theory 23:977-1004. doi: 10.1093/jopart/mus022

12. Dawes SS, Vidiasova L, Parkhimovich O (2016) Planning and designing open government data 
programs: An ecosystem approach. Gov Inf Q 33:15-27. doi: 10.1016/j.giq.2016.01.003

13. Sieber RE, Johnson PA (2015) Civic open data at a crossroads: Dominant models and current challenges. Gov Inf Q 32:308-315. doi: 10.1016/j.giq.2015.05.003

14. Johnson PA (2016) Reflecting on the Success of Open Data. Int J E-Planning Res 5:1-12. doi: 10.4018/IJEPR.2016070101

15. Lanzara F (2009) Building digital institutions: ICT and the rise of assemblages in government. In: UK PM (ed) Technol. Work Glob. pp 9-48

16. Hartley J, Alford J, Hughes O, Yates S (2015) Public value and political astuteness in the work of public managers: the art of the possible. Public Adm 93:195-211. doi: 10.1111/padm.12125

17. West K, Davis P (2011) What is the public value of government action? Towards a (new) pragmatic approach to values questions in public endeavours. Public Adm 89:226-241. doi: 10.1111/j.14679299.2010.01847.x

18. Benington J (2007) From private choice to public value.

19. O'Flynn J (2007) From New Public Management to Public Value: Paradigmatic Change and Managerial Implications. Aust J Public Adm 66:353-366. doi: 10.1111/j.14678500.2007.00545.x

20. Moore M (1995) Creating public value: Strategic management in government. Harvard University press

21. Ostrom E (1972) Metropolitan reform: Propositions derived from two traditions. Soc Sci Q 53:474-493.

22. Alford J (2002) Defining the Client in the Public Sector: A Social-Exchange Perspective. Public Adm Rev 62:337-346. doi: 10.1111/15406210.00183

23. Parrado S, Van Ryzin GG, Bovaird T, Löffler E (2013) Correlates of Co-production: Evidence From a Five-Nation Survey of Citizens. Int Public Manag J 16:85-112. doi: 10.1080/10967494.2013.796260

24. Verschuere B, Brandsen T, Pestoff V (2012) Coproduction: The State of the Art in Research and the Future Agenda. Volunt Int J Volunt Nonprofit Organ 23:1083-1101. doi: 10.1007/s11266-0129307-8

25. Bovaird T, Loeffler E (2012) From Engagement to Co-production: The Contribution of Users and Communities to Outcomes and Public Value. Voluntas 23:1119-1138. doi: 10.1007/s11266012-9309-6

26. Vamstad J (2012) Co-production and Service Quality: The Case of Cooperative Childcare in Sweden. Volunt Int J Volunt Nonprofit Organ 23:1173-1188. doi: 10.1007/s11266-012-9312-y

27. Bannister F, Connolly R (2014) ICT, public values and transformative government: A framework and programme for research. Gov Inf Q 31:119-128. doi: 10.1016/j.giq.2013.06.002
28. Lindsay C, Osbrone S, Bond S (2014) The "new public governance" and employability services in an era of crisis: challenges for third sector organizations in Scotland. Public Adm 92:192207. doi: 10.1111/padm.12051

29. Margetts H, Dunleavy P (2013) The second wave of digital-era governance: a quasi-paradigm for government on the Web. Philos Trans R Soc A Math Phys Eng Sci 371:20120382-20120382. doi: 10.1098/rsta.2012.0382

30. Kallinikos J (2011) Bureaucracy Under Siege: On information, collaboration and networks. In: Clegg SR, Harris M, Höpfl H (eds) Manag. Mod. Beyond Bur. Oxford University Press, Oxford,UK, pp 132-154

31. Benkler Y (2007) The wealth of networks: How social production transforms markets and freedom. Inf Econ Policy 19:278-282. doi: 10.1016/j.infoecopol.2007.03.001

32. EPA (2015) United States Environmental Protection Agency, "Air Sensor Toolbox for Citizen Scientists.” http://www2.epa.gov/airresearch/air-sensor-toolbox-citizen-scientists.

33. Center for Patent and Innovation (2008) Peer-toPatent, First Anniversary Report. New York, NY

34. Linders D (2012) From e-government to wegovernment: Defining a typology for citizen coproduction in the age of social media. Gov Inf Q 29:446-454. doi: 10.1016/j.giq.2012.06.003

35. Shirky C (2010) Cognitive Surplus. Penguin Press, New York, NY

36. Janssen M, Charalabidis Y, Zuiderwijk A (2012) Benefits, Adoption Barriers and Myths of Open Data and Open Government. Inf Syst Manag 29:258-268. doi: 10.1080/10580530.2012.716740

37. Conradie P, Choenni S (2014) On the barriers for local government releasing open data. Gov Inf Q. doi: 10.1016/j.giq.2014.01.003

38. Klievink B, Bharosa N, Tan YH (2016) The collaborative realization of public values and business goals: Governance and infrastructure of public-private information platforms. Gov Inf Q. doi: 10.1016/j.giq.2015.12.002

39. Benington J, Moore HM (2010) Public Value: Theory and Practice. Palgrave Macmillan

40. Chohan UW, Jacobs K (2016) Public Value in Politics: A Legislative Budget Office Approach. Int J Public Adm 1-11. doi: 10.1080/01900692.2016.1242612

41. Bryson J, Sancino A, Benington J, Sørensen E (2017) Towards a multi-actor theory of public value co-creation. Public Manag Rev 19:640-654. doi: 10.1080/14719037.2016.1192164

42. Hartley J, Alford J, Knies E, Douglas S (2017) Towards an empirical research agenda for public value theory. Public Manag Rev 19:670-685. doi: 10.1080/14719037.2016.1192166

43. Hartley J, Alford J, Hughes O, Yates S (2015) Public value and political astuteness in the work of public managers: the art of the possible. Public Adm 93:195-211. doi: 10.1111/padm.12125 
44. Page SB, Stone MM, Bryson JM, Crosby BC (2015) Public value creation by cross-sector collaborations: a framework and challenges of assessment. Public Adm 93:715-732. doi: 10.1111/padm. 12161

45. Bryson JM, Crosby BC, Bloomberg L (2014) Public Value Governance: Moving Beyond Traditional Public Administration and the New Public Management. Public Adm Rev 74:445456. doi: 10.1111/puar.12238

46. Lin Y (2015) Open data and co-production of public value of BBC Backstage. Int J Digit Telev 6:145-162. doi: 10.1386/jdtv.6.2.145_1

47. Alford J (2009) Public value from co-production by clients. Work Pap Melbourne, Aust New Zeal Sch Gov 1-23.

48. Alford J, Hughes O (2008) Public Value Pragmatism as the Next Phase of Public Management. Am Rev Public Adm 38:130-148. doi: 10.1177/0275074008314203

49. Callon M (1987) Society in the Making: The study of Technology as a Tool for Sociological Analysis. In: Soc. Constr. Technol. Syst. New Dir. Sociol. Hist. if Technol. pp 83-103

50. Latour B (1998) On Recalling ANT. Sociol Rev 46:15-25. doi: 10.1111/1467-954X.46.s.2

51. Orlikowski WJ (2007) Sociomaterial Practices: Exploring Technology at Work. Organ Stud 28:1435-1448.

52. Yin RK (1994) Case study research : design and methods. SAGE Publications, Inc; Fourth Edition edition (29 Dec. 2008), London

53. Leonardi PM, Barley SR (2010) What's Under Construction Here? Social Action, Materiality, and Power in Constructivist Studies of Technology and Organizing. Acad Manag Ann 4:1-51.

54. Hudson LA, Ozanne JL (1988) Alternative Ways of Seeking Knowledge in Consumer Research. J Consum Res 14:508. doi: 10.1086/209132

55. Fereday J, Muir-Cochrane E (2006) Demonstrating Rigor Using Thematic Analysis: A Hybrid Approach of Inductive and Deductive Coding and Theme Development. Int J Qual Methods 5:80-92.

56. Haas DF, Kraft DH (1984) Experimental and quasi-experimental designs for research in information science. Inf Process Manag 20:229237. doi: 10.1016/0306-4573(84)90053-0

57. Trochim WM (1989) Outcome pattern matching and program theory. Eval Program Plann 12:355366. doi: 10.1016/0149-7189(89)90052-9

58. Deloitte (2013) Market assessment of public sector information.

59. Hogge B (2016) Transport for London Get set,Go!

60. Sismondo S (1993) Some Social Constructions. Soc Stud Sci 23:515-553. doi: 10.1177/0306312793023003004

61. Cordella A, Paletti A, Shaikh M (2017) Renegotiating public value with co-production. Oxford University Press, Oxford,UK 